\title{
Prognostic Impact of Cancer Activity on Clinically Relevant Bleeding Events After Percutaneous Coronary Intervention: A Retrospective Study
}

\author{
Tatsuya Nishikawa \\ Osaka International Cancer Institute \\ Toshitaka Morishima \\ Osaka International Cancer Institute \\ Yuki Fujii \\ Osaka International Cancere Institute

\section{Sumiyo Okawa} \\ Osaka International Cancer Institute \\ Tomoyuki Otsuka \\ Osaka International Cancer Institute

\section{Risa Kamada} \\ Osaka International Cancer Institute

\section{Taku Yasui} \\ Osaka Internatinal Cancer Institute
}

\section{Wataru Shioyama}

Osaka Interenatinal Cancer Institute

Toru Oka

Osaka Internatinal Cancer Institute

Takahiro Tabuchi

Osaka International Cancer Institute

Masashi Fujita ( $\triangle$ masashi.fujita@oici.jp)

Osaka International Cancer Institute https://orcid.org/0000-0002-6924-1182

\section{Research}

Keywords: Antiplatelet therapy, Bleeding, Cancer, Percutaneous coronary intervention

Posted Date: May 18th, 2020

DOI: https://doi.org/10.21203/rs.3.rs-27825/v1

License: (c) (i) This work is licensed under a Creative Commons Attribution 4.0 International License. Read Full License 


\section{Abstract}

Background: Prevalence of cancer is a high risk factor for bleeding events related with antiplatelet therapy after percutaneous coronary intervention (PCl) in cancer patients. However, the long-term bleeding event rates have not been elucidated previously. Further risk stratification was not sufficiently assessed among cancer patients. This study aimed to evaluate the risk factors for clinically relevant bleeding events in cancer patients after PCl with stent implantation.

Methods: Among 236 patients who received PCl between 2013 and 2018, 89 cancer patients with first PCl with stent implantation, without prior dual-antiplatelet therapy (DAPT), were analyzed. They were divided into the active cancer $(n=44)$ and non-active cancer $(n=45)$ groups. The active cancer group included non-operable patients currently on treatment or those with metastasis. The non-active cancer group included patients who had already undergone radical surgery or had planned radical surgery within 3 months after the index PCl. The primary endpoint was bleeding events, characterized as Bleeding Academic Research Consortium (BARC) types 2, 3, and 5. The secondary endpoint was 3-point major adverse cardiovascular events (3PMACE) determined as the composite of cardiac death, nonfatal myocardial infarction, and nonfatal stroke.

Results: During the median follow-up period of 2.2 years, there were 11 patients with bleeding events, with only 1 patient in the non-active cancer group. Of the other 10 patients, 5 experienced bleeding during the dual-antiplatelet therapy (DAPT) period, while the remaining 5 experienced bleeding during the single-antiplatelet therapy (SAPT) period. The Kaplan-Meier analysis showed that the active cancer group had a significantly greater number of bleeding events of BARC types 2,3 , and 5 (log-rank, $P=0.010$ ). Multivariate Cox regression hazards model analysis revealed that cancer activity was an independent significant risk factor (HR, 9.03; 95\% Cl, 1.33-176.69; $\mathrm{P}=0.023$ ). During the 2.5-years [IQR: 0.7-3.0] follow-up period, there was no significant difference in the 3P-MACE between the active and non-active cancer patients.

Conclusions: The non-active cancer group presented with significantly lower clinically relevant bleeding after PCl than the active cancer patients. However, the bleeding risk was high in the active cancer groups during both the DAPT and SAPT periods.

\section{Background}

Cardiovascular diseases in cancer patients are currently attracting attention from both cardiologists and oncologists worldwide [1-3]. Recent developments in therapy have prolonged the prognosis of cancer patients. Along with this progress, cancer patients with concomitant cardiovascular diseases are increasing. Specifically, coronary artery disease (CAD) often coexists with cancer, as some risk factors (e.g., smoking) are common in both arteriosclerosis and cancer. Available evidence on CAD treatment in cancer patients is insufficient.

Irrespective of type, cancer induces a prothrombotic state, potentially leading to cancer-associated thrombosis [4, 5]. Furthermore, cancer patients have higher bleeding risks when treated with anti-thrombotic drugs for venous thromboembolism [6]. An increased risk of bleeding due to anticoagulation therapy with direct oral anticoagulants (DOAC) or warfarin has been reported [7-11]. Percutaneous coronary intervention (PCI) with stent implantation, which requires extended treatment with dualantiplatelet therapy (DAPT) followed by single-antiplatelet therapy (SAPT), is often performed as treatment for CAD in cancer patients. A few studies have reported that cancer patients experienced a higher bleeding rate after PCI $[12,13]$. Nevertheless, the long-term prognostic bleeding risk of DAPT or SAPT in cancer patients has been rarely reported in the past, and the actual bleeding risk in cancer patients following PCI procedures is unknown. Therefore, we investigated the risk factors for clinically relevant bleeding events in cancer patients after $\mathrm{PCl}$ with stent implantation.

\section{Methods}

\section{Study Population}

The present study was conducted in accordance with the Declaration of Helsinki and ethical standards, and the study protocol was approved by the local ethics committee of Osaka International Cancer Institute (approval no. 19046). The requirement for acquisition of informed consent was waived owings to the retrospective nature of the study. 
Patients who were diagnosed with certain cancer and who received PCI from 2013 to 2018 at Osaka International Cancer Institute were enrolled in this study. Patients (1) who had undergone either PCl with stent implantation or coronary artery bypass grafting before 2013, (2) who died of cancer within 1 month and did not have bleeding events, (3) who had malignant hematologic neoplasms, or (4) who were treated with DAPT prior to the index PCI were excluded. Baseline clinical data and outcomes were obtained from medical records. Patients were followed-up up to 3 years after the index PCl. All PCl procedures were performed by professional interventionists.

Chronic kidney disease was defined as an estimated glomerular filtration rate of $<60 \mathrm{~mL} / \mathrm{min} / 1.73 \mathrm{~m}^{2}$ for $>6$ months. Overweight was defined as body mass index $>25 \mathrm{~kg} / \mathrm{m}^{2}$.

\section{Definitions of Primary and Secondary Endpoints}

The primary endpoint of the study was bleeding events, which were categorized into Bleeding Academic Research Consortium (BARC) types 2, 3, and 5 [14]. Bleeding events included intracranial bleeding and gastrointestinal or colorectal bleeding requiring endoscopic hemostasis, as well as any bleeding requiring blood transfusion, hospitalization, any medical care or death caused by bleeding. Evidence of cardiac ischemia was determined by fractional flow reserve, myocardial scintigraphy, or angiographical stenosis $>90 \%$ according to the American Heart Association classification. Only patients with clinically proven ischemia underwent $\mathrm{PCl}$ with stent implantation. As the secondary endpoint, 3-point major adverse cardiovascular events (3P-MACEs) were defined as cardiac death, nonfatal myocardial infarction (MI), and nonfatal stroke.

\section{Definition of Active Cancer and Non-active Cancer}

For individuals with multiple primary cancers, the most recently diagnosed cancer was counted. The activity status of cancer was categorized according to operability for radical surgery. The non-active cancer group included patients who already underwent radical surgery or endoscopic cancer resection, as well as those who had planned radical surgery within 3 months after and within 5 years before the index PCl. Active cancer was determined as cancer currently treated with chemotherapy and/or radiation therapy with no indication for radical surgery for any reason. One reason for this categorization of two groups was that operable patients could possibly have characteristics similar to those of patients without cancer after radical surgery. In addition, we included patients who had planned to have radical surgery "within 3 months" because the current guidelines recommend 3 months of DAPT for high bleeding risk patients, such as those with cancer.

\section{Data Analysis}

Continuous data are reported as means \pm standard deviation (SD) and prevalence is expressed as (\%). Categorical data were compared using the chi-squared test or Fisher exact test. For DAPT duration, which was not normally distributed, data were compared using the Wilcoxon signed-rank test. Event-free survival (EFS) relative to bleeding, all-cause death, and 3P-MACE was assessed using Kaplan-Meier survival analysis, and differences between groups were compared using the log-rank test. The risk of developing bleeding events and 3P-MACE were estimated by hazard ratio (HR) and their $95 \%$ confidence intervals (CI) based on Cox proportional hazards models. Variables with $\mathrm{P}<0.1$ in univariate analysis were included in a multivariate model to identify independent risk factors. For statistical analysis, $P<0.05$ was considered statistically significant. Due to the small sample size, some factors could not be assessed by Cox regression hazards models and were indicated as "NA." All statistical analyses were performed using JMP version 11.0 (SAS Inc., Tokyo, Japan).

\section{Results}

\section{Baseline Characteristics of Study Participants}

Data of 236 patients subjected to $\mathrm{PCl}$ with stent implantation from 2013 to 2018 were collected. Of these, 84 non-cancer patients and 50 patients who underwent $\mathrm{PCl}$ with stent implantation before 2013 were excluded. Patients with malignant lymphoma and leukemia, those who died of cancer within 1 month after PCl, and those who received DAPT before PCl for any reasons were excluded. Finally, 89 patients were categorized into either the active cancer group $(n=45)$ or the non-active cancer group $(n=44)$ (Figure 1). Within the non-active cancer group, 17 out of 44 patients underwent radical surgery at $<3$ months after the index $\mathrm{PCl}$, 
19 underwent radical surgery at $<6$ months, 2 at $<12$ months, and 6 at $<5$ years before PCl. During the follow-up period, 11 bleeding events, 8 3P-MACEs, and 18 all-cause deaths occurred.

The baseline characteristics of all patients and for each group are summarized in Table 1. The prevalence of acute coronary syndrome (ACS) and atrial fibrillation (AF), average left ventricular ejection fraction, and oral anticoagulant use were significantly different between the groups. The percentage of drug-eluting stent (DES) implantation over bare metal stent (BMS) was not significantly different between the groups. For prognostic assessment, the median follow-up period was 2.2 years [interquartile range (IQR): 0.7-3.0 years] for the primary endpoint and 2.5 years [IQR: 0.7-3.0] for the secondary endpoint. Kaplan-Meier analysis for all-cause death as the preferred indicator of prognosis for these 2 groups is shown in Figure 2. The all-cause death rate in 3 years was much higher in the active cancer group than in the non-active cancer group (log-rank test, $P=0.018$ ), which was most likely caused by differences in cancer stages, as indicated by the prevalence of metastasis in Table 1.

\section{Risk Assessment for Clinically Relevant Bleeding (BARC Types 2, 3, and 5)}

In the present study, 11 patients presented with bleeding of BARC types 2, 3, and 5 after PCl. The characteristics are shown in Tables 2 and 3. All patients were males and the cancer types varied. Intracranial bleeding occurred in 2 out of 11 patients, whereas gastrointestinal bleeding was identified in 8 out of 11 patients. The antiplatelet therapies used when the events occurred are indicated in Table 3. Bleeding events were observed not only during the DAPT period but also during SAPT regardless of anticoagulant intake. Among 45 active cancer patients, 8 received DOAC; of these, 2 (25\%) patients experienced bleeding events at $<3$ years. Furthermore, among the remaining 37 active cancer patients who did not receive DOAC, 5 (14\%) patients experienced bleeding events during DAPT and an additional $3(8 \%)$ patients had bleeding events during the SAPT period (Tables 2 and 3 ). All 8 patients who had gastrointestinal bleeding events received proton pump inhibitors (data no shown).

As the primary endpoint, EFS and rate of bleeding events categorized as BARC types 2, 3, and 5 were assessed. The occurrence rates of events during the follow-up period (median, 2.2 years) were $2 \%$ and $22 \%$ for the non-active and active cancer groups, respectively. As shown in Figure 3a, the bleeding rate was lower in the non-active cancer group than in the active cancer group (log-rank test, $\mathrm{P}=0.002$ ). The risk of BARC types 2, 3, and 5 bleeding in non-active cancer was low, with only 1 out of 11 patients in the non-active group experiencing a bleeding event. Among them, 5 patients had bleeding events during chemotherapy. However, only 1 patient had a low platelet count $(48,000 / \mu \mathrm{L})$, whereas others had a platelet count of more than $100,000 / \mu \mathrm{L}$.

Next, we assessed significant clinical prognostic factors for bleeding in these cancer patients (Table 4). The presence of active cancer $(H R, 12.81 ; 95 \% \mathrm{Cl}, 2.44-235.57 ; \mathrm{P}=0.001)$ and the prevalence of metastasis $(\mathrm{HR}, 5.23 ; 95 \% \mathrm{Cl}, 1.54-18.50 ; \mathrm{P}<0.001)$ were significant prognostic factors in Cox proportional hazards models. Other clinical characteristics, such as history, cardiac function, CAD-related medications, and PCl-related factors were not significant. Further, DAPT duration and stent type (DES or BMS) were not significant prognostic factors for bleeding events. Multivariate analysis revealed that only active cancer was a significant independent risk factor for bleeding events ( $\mathrm{HR}, 9.03 ; 95 \% \mathrm{Cl}, 1.33-176.69 ; \mathrm{P}=0.023)$.

\section{Risk Assessment for 3P-MACE}

We also assessed the 3P-MACE rate as a secondary endpoint in the 2 groups. There were no significant differences in DAPT duration, percentage of ACS, and history of previous MI or cerebral infarction between the 2 groups (Table 1). The occurrence rates of events during the follow-up period (median, 2.5 years) were $2 \%$ and $6 \%$ for the non-active and active cancer groups, respectively. Overall, 3P-MACE was present in $9 \%$ of patients and Kaplan-Meier analysis did not show significant difference between the 2 groups (Figure $3 b$ ). Additionally, Cox proportional hazards models did not indicate the significance of active cancer as a prognostic factor (Table 5). ACS, number of stents, total length of stents, and left ventricular ejection fraction tended to be related to 3P-MACE $(P<0.10)$. Furthermore, multivariate analysis showed that these factors were not significant risk factors for 3P-MACE.

\section{Discussion}

The key findings of our study are as follows: (i) Non-active cancer patients, based on our definition, have significantly lower bleeding rates than active cancer patients. (ii) Bleeding after PCl could occur during both the DAPT and SAPT periods. (iii) The 
majority of bleeding sites involved the gastrointestinal tract.

In our definition of non-active cancer, patients scheduled for radical surgery within 3 months were included in addition to patients who had already received interventions. In the real-world clinical setting, CAD is often diagnosed during preoperative examination for cancer surgery; at this time point, cardiologists and oncologists make difficult decisions regarding when to perform PCl. It has been reported that historically, cancer patients experienced fewer in-hospital bleeding events than current cancer patients with prostate, colon, and lung cancer [15]. As cancer patients are known to have a higher bleeding risk, a better stratification of risk for cancer patients is needed. As indicated in the European Society of Cardiology guidelines [16], the recommended DAPT duration after $\mathrm{PCl}$ for stable CAD in high bleeding risk patients is 3 months. Thus, we defined " $\mathrm{PCl}<3$ months before planned radical surgery" as non-active cancer patients for further stratification of bleeding risk. Nonetheless, active cancer is sometimes difficult to define. However, whether the patients are eligible for or have already had radical surgery could be an easy and clear indicator of risk stratification. Therefore, we chose the criteria for "active" and "non-active" cancer of the present study accordingly.

One of the major differences in the baseline characteristics of the 2 groups was the prevalence of ACS. In the present study, the prevalence of ACS was higher in the active cancer group than in the non-active cancer group. This finding was reasonable because ACS should be treated with primary $\mathrm{PCl}$ even in active cancer patients; more non-active cancer patients underwent $\mathrm{PCl}$ for stable CAD because of their relatively better prognosis.

\section{Impact of Activeness of Cancer on Bleeding Event Rates in Patients After PCl}

Several studies have reported bleeding risks after PCI largely in ischemic heart disease patients without cancer. The 1-year outcomes of bleeding of BARC types 2 and 3 were observed in $3.6 \%$ and $1.8 \%$ of patients, respectively [17]. Another study reported the bleeding risk for 3 months of DAPT (ticagrelor and aspirin), followed by randomized assignment to the ticagrelor plus placebo group or continuation of DAPT group. The risk of BARC type 3 or 5 bleeding at 1 year was reported to be $1.0 \%$ for the placebo group and $2.0 \%$ for the DAPT group [18]. Furthermore, in the AFIRE study, bleeding risk was the safety endpoint of rivaroxaban monotherapy or single antiplatelet plus rivaroxaban for AF patients and those who underwent $\mathrm{PCl}$ at $>1$ year earlier

[19]. The study reported bleeding event rates of $1.62 \%$ and $2.76 \%$ per patient-year for the rivaroxaban monotherapy group and the single antiplatelet plus rivaroxaban group, respectively. When considering cancer patients, it is easy to imagine that advanced cancer patients had more bleeding events. Nevertheless, the available evidence for bleeding events after PCl is limited. In one of the few studies involving cancer patients who underwent $\mathrm{PCl}$, the prevalence of cancer was an independent determinant of cumulative incidence of hospitalization for bleeding [12]. Another important study reported the bleeding risks of DAPT among 9240 ACS patients on DAPT with a median follow-up period of 17 months such that $1.8 \%$ patients had a confirmed neoplasm event, and the rate of Global Use of Strategies to Open Occluded Coronary Arteries severe/moderate bleeding was higher in those with neoplasms than in those without neoplasms (11.2 vs. 1.5\%) [13]. Considering the follow-up period, the bleeding event rate of $11.2 \%$ was similar to that for our active cancer group (22\%).

Our study, taken together with previous studies, indicates that non-active cancer patients experienced lower rates of BARC types 2 , 3 , and 5 bleeding events (2\%), which is similar to the results of previous studies mostly involving non-cancer patients. Conversely, active cancer patients had a relatively higher bleeding rate (22\%) than those without a cancer history, but they had a consistent bleeding rate compared to those with neoplasms, as reported previously.

\section{Impact of Activeness of Cancer on 3P-MACE Rates in Patients After PCI}

As the secondary endpoint, we assessed the 3P-MACE rate in the 2 groups. There was no difference between active and nonactive cancer groups according to both Kaplan-Meier and Cox regression hazards model analyses. The rates of 3P-MACE were $5 \%$ and $13 \%$ in the non-active and active cancer groups, respectively after a median follow-up period of 2.5 years. According to the AFIRE study [19], the rate of MACE including stroke, MI, unstable angina requiring PCl, and all-cause death was $4.14 \%$ per year for the DOAC monotherapy group and 5.75\% per year for DOAC plus SAPT group. Patients after PCI with hypertension had significantly higher 2-year rates of MACE (cardiac death, $\mathrm{MI}$, or stent thrombosis) than patients without hypertension ( $7.0 \%$ vs. 4.4\%) [20]. Additionally, in the AUGUSTUS study, AF patients who underwent elective PCl experienced $5.6 \%$ and $5.4 \%$ of death or ischemic events (stroke, $\mathrm{Ml}$, stent thrombosis, and urgent revascularization), respectively, when treated with apixaban or vitamin $\mathrm{K}$ 
antagonist plus P2Y12 inhibitor over at least 6-month follow-up [21]. The composite endpoint of cardiovascular death, MI, and stroke was reported to occur more frequently in patients with neoplasm than in those without (18.2\% vs. 13.5\%) [13]. Compared to that in previous studies, the 3P-MACE rate in our cancer patients seemed to be reasonable and was not higher than the rate in studies that included mostly non-cancer patients.

\section{Implications for Patients Undergoing PCl}

In the real-world clinical setting, it is difficult for cardiologists to decide on the timing of $\mathrm{PCl}$ and cancer surgery. Furthermore, DAPT duration after PCI is controversial. In our study, patients with BMS received 1 month of DAPT and those with DES received 6 to 12 months of DAPT. As reported by the STOPDAPT-2 study, a short DAPT duration significantly reduced bleeding events after PCl; thus, DAPT duration has been reduced for PCl in non-cancer patients. However, bleeding events during the SAPT period were also detected during the 3-year follow-up period. In addition, although bleeding was mostly from the digestive tract, the primary cancers also included the lung, renal, larynx, and pharynx. There are 2 major risk stratifications of bleeding after PCl, the PRECISE DAPT score [22] and the Academic Research Consortium High Bleeding Risk (ARC-HBR) criteria [23]. The PRECISE DAPT score may not provide additional information on cancer patients, because the scores and criteria include the white blood cell count, hemoglobin, and platelet levels, which are unstable in patients undergoing chemotherapy. Although the ARC-HBR criteria include the presence of cancer as a bleeding risk factor, we now need further risk stratification of cancer patients since the results of accumulated evidence have shown that cancer patients have a higher bleeding risk than cancer-naïve patients. However, our study may contribute to the improvement in decision-making with respect to indications for PCl in cancer patients.

\section{Limitations}

The present study was a retrospective observational study with a relatively small sample size; thus, it was underpowered for the evaluation of clinical outcomes such as bleeding or MACE. As our institute does not have an emergency room and all patients who come to our institute are cancer patients, the number of $\mathrm{PCl}$ procedures was relatively low. However, all PCI procedures were performed by well-trained and certified interventionists. Another limitation was that since cancer type varied in each group, the effects of cancer type could not be considered due to the small sample size. Furthermore, as the event rate was very low, some factors could not be correctly assessed in Cox regression hazards model analysis.

\section{Conclusion}

Our study suggests that post-PCI bleeding in non-active cancer patients may not be a cause for concern; however, closer attention should be paid on bleeding events during SAPT to the same degree as during DAPT in active cancer patients.

\section{Abbreviations}

CAD, coronary artery disease; DOAC, direct oral anticoagulants; PCl, percutaneous coronary intervention; DAPT, dual-antiplatelet therapy; SAPT, single-antiplatelet therapy; BARC, Bleeding Academic Research Consortium; 3P-MACEs, 3-point major adverse cardiovascular events; MI, myocardial infarction; SD, standard deviation; $\mathrm{EFS}$, event-free survival; $\mathrm{HR}$, hazard ratio; $\mathrm{Cl}$, confidence interval; ACS, acute coronary syndrome; AF, atrial fibrillation; DES, drug-eluting stent; BMS, bare metal stent; IQR, interquartile range; ARC-HBR, Academic Research Consortium High Bleeding Risk

\section{Declarations}

\section{Ethics approval and consent to participate}

The study protocol was approved by the local ethics committee of Osaka International Cancer Institute (approval no. 19046). The requirement for acquisition of informed consent was waived owing to the retrospective nature of the study.

\section{Consent for publication}

The requirement for acquisition of informed consent was waived owing to the retrospective nature of the study. 
Availability of data and materials

The datasets used and analyzed during the current study are available from the corresponding author on reasonable request.

\section{Competing interests}

The authors declare that they have no conflicts of interest.

\section{Funding}

This work was supported by JSPS KAKENHI (grant no. JP19K17465 to T.N. and no. JP16K09470 to T.0.).

\section{Authors' contributions}

TN, TM, and MF wrote manuscript. Tomoyuki $O$ assessed cancer data. TM, SO, and TT helped statistical analysis. YF, RK, TY, WS, and Toru $\mathrm{O}$ helped in the development and revision of the manuscript.

\section{Acknowledgments}

This work was supported by JSPS KAKENHI (grant no. JP19K17465 to T.N. and no. JP16K09470 to T.0.).

\section{References}

1. Abe J, Martin JF, Yeh ET. The future of onco-cardiology: We are not just "side effect hunters". Circ Res. 2016;119:896-9.

2. Sueta D, Hokimoto S. Onco-cardiology: Present and future. Int J Cardiol. 2016;215:38-40.

3. Hayek SS, Ganatra S, Lenneman C, Scherrer-Crosbie M, Leja M, Lenihan DJ, et al. Preparing the cardiovascular workforce to care for oncology patients: JACC review topic of the week. J Am Coll Cardiol. 2019;73:2226-35.

4. Mitrugno A, Tormoen GW, Kuhn P, McCarty OJ. The prothrombotic activity of cancer cells in the circulation. Blood Rev. 2016;30:11-9.

5. Di Nisio M, Lee AY, Carrier M, Liebman HA, Khorana AA. Diagnosis and treatment of incidental venous thromboembolism in cancer patients: guidance from the SSC of the ISTH. J Thromb Haemost. 2015;13:880-3.

6. Prandoni P, Lensing AW, Piccioli A, Bernardi E, Simioni P, Girolami B, et al. Recurrent venous thromboembolism and bleeding complications during anticoagulant treatment in patients with cancer and venous thrombosis. Blood. 2002;100:3484-8.

7. Yasui T, Shioyama W, Oboshi M, Oka T, Fujita M. Oral anticoagulants in Japanese patients with atrial fibrillation and active cancer. Intern Med. 2019;58:1845-9.

8. Young AM, Marshall A, Thirlwall J, Chapman O, Lokare A, Hill C, et al. Comparison of an oral factor Xa inhibitor with low molecular weight heparin in patients with cancer with venous thromboembolism: Results of a randomized trial (SELECT-D). J Clin Oncol. 2018;36:2017-23.

9. Agnelli G, Becattini C, Bauersachs R, Brenner B, Campanini M, Cohen A, et al. Apixaban versus dalteparin for the treatment of acute venous thromboembolism in patients with cancer: The Caravaggio Study. Thromb Haemost. 2018;118:1668-78.

10. Kraaijpoel N, Di Nisio M, Mulder FI, van Es N, Beyer-Westendorf J, Carrier M, et al. Clinical impact of bleeding in cancerassociated venous thromboembolism: Results from the Hokusai VTE Cancer Study. Thromb Haemost. 2018;118:1439-49.

11. McBane li R, Loprinzi CL, Ashrani A, Perez-Botero J, Leon Ferre RA, Henkin S, et al. Apixaban and dalteparin in active malignancy associated venous thromboembolism. The ADAM VTE Trial. Thromb Haemost. 2017;117:1952-61.

12. Ko DT, Yun L, Wijeysundera HC, Jackevicius CA, Rao SV, Austin PC, et al. Incidence, predictors, and prognostic implications of hospitalization for late bleeding after percutaneous coronary intervention for patients older than 65 years. Circ Cardiovasc Interv. 2010;3:140-7.

13. Roe MT, Cyr DD, Eckart D, Schulte PJ, Morse MA, Blackwell KL, et al. Ascertainment, classification, and impact of neoplasm detection during prolonged treatment with dual antiplatelet therapy with prasugrel vs. clopidogrel following acute coronary syndrome. Eur Heart J. 2016;37:412-22. 
14. Mehran R, Rao SV, Bhatt DL, Gibson CM, Caixeta A, Eikelboom J, et al. Standardized bleeding definitions for cardiovascular clinical trials: a consensus report from the Bleeding Academic Research Consortium. Circulation. 2011;123:2736-47.

15. Potts JE, Iliescu CA, Lopez Mattei JC, Martinez SC, Holmvang L, Ludman P, et al. Percutaneous coronary intervention in cancer patients: a report of the prevalence and outcomes in the United States. Eur Heart J. 2019;40:1790-800.

16. Valgimigli M, Bueno H, Byrne RA, Collet JP, Costa F, Jeppsson A, et al. 2017 ESC focused update on dual antiplatelet therapy in coronary artery disease developed in collaboration with EACTS: The Task Force for dual antiplatelet therapy in coronary artery disease of the European Society of Cardiology (ESC) and of the European Association for Cardio-Thoracic Surgery (EACTS). Eur Heart J. 2018;39:213-60.

17. Sharma PK, Chhatriwalla AK, Cohen DJ, Jang JS, Baweja P, Gosch K, et al. Predicting long-term bleeding after percutaneous coronary intervention. Catheter Cardiovasc Interv. 2017;89:199-206.

18. Mehran R, Baber U, Sharma SK, Cohen DJ, Angiolillo DJ, Briguori C, et al. Ticagrelor with or without aspirin in high-risk patients after PCl. N Engl J Med. 2019;381:2032-42.

19. Yasuda S, Kaikita K, Akao M, Ako J, Matoba T, Nakamura M, et al. Antithrombotic therapy for atrial fibrillation with stable coronary disease. N Engl J Med. 2019;381:1103-13.

20. Redfors B, Chen S, Ben-Yehuda O, Huang X, Witzenbichler B, Weisz G, et al. Association between hypertension, platelet reactivity, and the risk of adverse events after percutaneous coronary intervention (from the ADAPT-DES Study). Am J Cardiol. 2019;124:1380-8.

21. Vora AN, Alexander JH, Wojdyla D, Aronson R, Granger CB, Darius H, et al. Hospitalization among patients with atrial fibrillation and a recent acute coronary syndrome or percutaneous coronary intervention treated with apixaban or aspirin: Insights from the AUGUSTUS Trial. Circulation. 2019;140:1960-3.

22. Costa F, van Klaveren D, James S, Heg D, Raber L, Feres F, et al. Derivation and validation of the predicting bleeding complications in patients undergoing stent implantation and subsequent dual antiplatelet therapy (PRECISE-DAPT) score: a pooled analysis of individual-patient datasets from clinical trials. Lancet. 2017;389:1025-34.

23. Urban P, Mehran R, Colleran R, Angiolillo DJ, Byrne RA, Capodanno D, et al. Defining high bleeding risk in patients undergoing percutaneous coronary intervention: a consensus document from the Academic Research Consortium for High Bleeding Risk. Eur Heart J. 2019;40:2632-53.

\section{Tables}

Table 1. Baseline Characteristics of All Patients, Non-active Cancer Patients, and Active Cancer Patients. 


\begin{tabular}{|c|c|c|c|c|c|c|c|c|c|}
\hline \multirow[b]{2}{*}{ Age } & \multicolumn{2}{|c|}{$\begin{array}{l}\text { All patients } \\
(n=89)\end{array}$} & \multicolumn{3}{|c|}{$\begin{array}{l}\text { Non-active cancer } \\
(n=44)\end{array}$} & \multicolumn{3}{|c|}{$\begin{array}{l}\text { Active cancer } \\
(n=45)\end{array}$} & \multirow{2}{*}{$\begin{array}{l}P \text {-value } \\
0.548\end{array}$} \\
\hline & 71 & 7.4 & 72 & \pm & 7.0 & 71 & \pm & 7.8 & \\
\hline Male sex & 76 & (85) & 38 & \multicolumn{2}{|c|}{ (86) } & 38 & \multicolumn{2}{|c|}{ (84) } & 1.000 \\
\hline ACS & 12 & (13) & 1 & \multicolumn{2}{|l|}{ (2) } & 11 & \multicolumn{2}{|c|}{ (24) } & 0.004 \\
\hline Drug eluting stent & 57 & (64) & 29 & \multicolumn{2}{|c|}{ (66) } & 28 & \multicolumn{2}{|c|}{$(62)$} & 0.826 \\
\hline Atrial fibrillation & 9 & (10) & 1 & \multicolumn{2}{|l|}{$(2)$} & 8 & \multicolumn{2}{|c|}{ (18) } & 0.030 \\
\hline Multivessel disease & 26 & $(29)$ & 13 & \multicolumn{2}{|c|}{$(30)$} & 13 & \multicolumn{2}{|c|}{$(29)$} & 1.000 \\
\hline Number of implanted stents & 1.3 & 0.7 & 1.3 & \pm & 0.5 & 1.4 & \pm & 0.1 & 0.287 \\
\hline Total length of the stent(s) & 28 & $(20-39)$ & 28 & \multicolumn{2}{|c|}{$(20-40)$} & 28 & \multicolumn{2}{|c|}{$(24-40)$} & 0.263 \\
\hline LAD PCI & 56 & (63) & 28 & \multicolumn{2}{|c|}{ (64) } & 28 & \multicolumn{2}{|c|}{$(62)$} & 1.000 \\
\hline DAPT duration, median (IQR) (m) & 9 & $(3-12)$ & 10 & \multicolumn{2}{|c|}{$(3-12)$} & 8 & $(3-1$ & & 0.558 \\
\hline Chronic kidney disease & 26 & $(29)$ & 14 & $(32)$ & & 12 & $(27)$ & & 0.646 \\
\hline Hypertension & 59 & $(66)$ & 28 & $(64)$ & & 31 & $(69)$ & & 0.658 \\
\hline Dyslipidemia & 50 & $(56)$ & 25 & $(57)$ & & 25 & $(56)$ & & 1.000 \\
\hline Diabetes mellitus & 39 & $(44)$ & 17 & (39) & & 22 & $(49)$ & & 0.395 \\
\hline Current smoking & 14 & (16) & 7 & (16) & & 7 & (16) & & 1.000 \\
\hline Overweight & 12 & (13) & 4 & (9) & & 8 & (18) & & 0.353 \\
\hline History of & & & & & & & & & \\
\hline Cerebral infarction & 10 & (11) & 3 & (7) & & 7 & $(16)$ & & 0.315 \\
\hline Intracranial bleeding & 2 & $(2)$ & 0 & $(0)$ & & 2 & (4) & & 0.495 \\
\hline Myocardial infarction & 10 & (11) & 3 & (7) & & 7 & (16) & & 0.315 \\
\hline Congestive heart failure & 9 & $(10)$ & 3 & (7) & & 6 & (13) & & 0.485 \\
\hline Echocardiography & & & & & & & & & \\
\hline LVEF (\%) & 65 & \pm & 66 & \pm & 7.5 & 63 & \pm & 10.0 & 0.085 \\
\hline LV end diastolic diameter (mm) & 46 & 5 & 46 & \pm & 4.7 & 45 & \pm & 5.2 & 0.873 \\
\hline LV end systolic diameter (mm) & 29 & \pm & 29 & \pm & 4.8 & 30 & \pm & 5.5 & 0.404 \\
\hline Mitral regurgitation $\geq$ type 3 & 2 & $(2)$ & 1 & $(2)$ & & 1 & $(2)$ & & 1.000 \\
\hline Medication & & & & & & & & & \\
\hline Oral anti-coagulant & 9 & $(10)$ & 1 & (2) & & 8 & (18) & & 0.030 \\
\hline$\beta$-blocker & 43 & $(48)$ & 21 & $(48)$ & & 22 & $(49)$ & & 1.000 \\
\hline ACE-I/ARB & 28 & (31) & 11 & $(25)$ & & 17 & (38) & & 0.255 \\
\hline Diuretics & 5 & $(6)$ & 1 & $(2)$ & & 4 & (9) & & 0.361 \\
\hline Statins & 70 & (79) & 35 & $(80)$ & & 35 & $(78)$ & & 1.000 \\
\hline
\end{tabular}




\begin{tabular}{lllllll} 
Cancer type & 33 & $(37)$ & 24 & $(55)$ & 9 & $(20)$ \\
\hline Digestive tract & 16 & $(18)$ & 7 & $(16)$ & 9 & $(20)$ \\
\hline Urinary organs, prostate & 5 & $(6)$ & 1 & $(2)$ & 4 & $(9)$ \\
\hline Head, neck & 6 & $(7)$ & 3 & $(7)$ & 3 & $(7)$ \\
\hline Breast & 14 & $(16)$ & 4 & $(9)$ & 10 & $(22)$ \\
\hline Liver, bile, pancreas & 13 & $(15)$ & 3 & $(7)$ & 10 & $(22)$ \\
\hline Lung, bronchus & 2 & $(2)$ & 2 & $(5)$ & 0 & $(0)$ \\
\hline Bone, muscle & 23 & $(24)$ & 0 & $(0)$ & 23 & $(53)$
\end{tabular}

Data are presented as means \pm standard deviation or $n(\%)$. P-values are for non-active cancer group vs. active cancer group. Continuous data were analyzed by two-sided Student t-tests. Categorical data were analyzed by Fisher exact test. *Wilcoxon signed-rank test.

ACS, acute coronary syndrome; PCl, percutaneous coronary intervention; LAD, left anterior descending artery; DAPT, dual antiplatelet therapy; LVEF, left ventricular ejection fraction; ACE-I, angiotensin-converting-enzyme inhibitor; ARB, angiotensin II receptor blocker

Table 2. Characteristics of the Patients with Bleeding Events 


\begin{tabular}{|c|c|c|c|c|c|c|c|c|c|c|c|}
\hline $\begin{array}{l}\text { Case } \\
\#\end{array}$ & Age & Sex & $\begin{array}{l}\text { Primary } \\
\text { cancer }\end{array}$ & Stage & ACS & OAC & $\begin{array}{l}\text { DAPT } \\
\text { duration } \\
\text { (months) }\end{array}$ & $\begin{array}{l}\text { PCl to } \\
\text { bleeding } \\
\text { event } \\
\text { (days) }\end{array}$ & $\begin{array}{l}\text { Bleeding } \\
\text { during } \\
\text { DAPT }\end{array}$ & $\begin{array}{l}\text { Active } \\
\text { cancer }\end{array}$ & Bleeding site \\
\hline 1 & 73 & Male & NSCLC & III & - & + & 11 & 659 & - & + & Intracranial \\
\hline 2 & 58 & Male & Pancreas & IV & - & - & 8 & 224 & + & + & Intracranial \\
\hline 3 & 80 & Male & Gastric & IV & - & - & 1 & 13 & + & + & $\begin{array}{l}\text { Upper } \\
\text { gastrointestinal } \\
\text { tract }\end{array}$ \\
\hline 4 & 77 & Male & NSCLC & II & - & - & 34 & 414 & + & + & $\begin{array}{l}\text { Upper } \\
\text { gastrointestinal } \\
\text { tract }\end{array}$ \\
\hline 5 & 76 & Male & Pharyngeal & I & - & - & 8 & 112 & + & + & $\begin{array}{l}\text { Upper } \\
\text { gastrointestinal } \\
\text { tract }\end{array}$ \\
\hline 6 & 68 & Male & Laryngeal & III & - & + & 12 & 576 & - & + & $\begin{array}{l}\text { Lower digestive } \\
\text { tract }\end{array}$ \\
\hline 7 & 63 & Male & Renal & IV & + & - & 19 & 1189 & - & + & $\begin{array}{l}\text { Upper } \\
\text { gastrointestinal } \\
\text { tract }\end{array}$ \\
\hline 8 & 54 & Male & Gastric & IV & - & - & 3 & 216 & - & + & $\begin{array}{l}\text { Upper } \\
\text { gastrointestinal } \\
\text { tract }\end{array}$ \\
\hline 9 & 68 & Male & Pancreas & IV & - & - & 3 & 108 & - & + & $\begin{array}{l}\text { Upper } \\
\text { gastrointestinal } \\
\text { tract }\end{array}$ \\
\hline 10 & 78 & Male & Pancreas & ॥ & - & - & 2 & 83 & - & - & $\begin{array}{l}\text { Upper } \\
\text { gastrointestinal } \\
\text { tract }\end{array}$ \\
\hline 11 & 81 & Male & NSCLC & IV & - & - & 4 & 72 & + & + & Unknown \\
\hline
\end{tabular}

ACE, acute coronary syndrome; DAPT, dual-antiplatelet therapy; NSCLC, non-small cell lung cancer; OAC, oral anticoagulant; PCI, percutaneous coronary intervention

Table 3. Relationship between OAC, Antiplatelet Therapy, and Event Rates

\begin{tabular}{|c|c|c|c|c|c|c|c|c|c|c|c|}
\hline \multirow[b]{4}{*}{ BARC types } & \multicolumn{5}{|c|}{ Non-active cancer $(n=44)$} & \multicolumn{6}{|c|}{ Active cancer $(n=45)$} \\
\hline & \multicolumn{2}{|c|}{ OAC (+) (n=1) } & \multicolumn{3}{|c|}{ OAC $(-)(n=43)$} & \multicolumn{3}{|c|}{ OAC (+) (n=8) } & \multicolumn{3}{|c|}{ OAC (-) (n=37) } \\
\hline & DAPT & SAPT & DAPT & \multicolumn{2}{|c|}{ SAPT } & DAPT & \multicolumn{2}{|c|}{ SAPT } & \multicolumn{2}{|c|}{ DAPT } & SAPT \\
\hline & $(0)$ & (0) & $(0)$ & 1 & (2.3) & $(0)$ & 2 & $(25.0)$ & 5 & (13.5) & (8.1) \\
\hline 2,3 , and 5 & & & & & & & & & & & \\
\hline 3P-MACE & $(0)$ & $(0)$ & $(4.7)$ & 0 & $(0)$ & $(12.5)$ & 2 & $(25.0)$ & 3 & (8.1) & $(0)$ \\
\hline
\end{tabular}

BARC, Bleeding Academic Research Consortium; DAPT, dual-antiplatelet therapy; MACE, major adverse cardiovascular event; OAC, oral anticoagulant; SAPT, single-antiplatelet therapy; OAC, oral anticoagulant

Table 4. Cox Regression Hazards Model Analysis for Bleeding Events of BARC Types 2, 3 and 5 
Univariate analysis

Multivariate analysis

\begin{tabular}{|c|c|c|c|c|c|c|}
\hline BARC types 2 and 3 & HR & {$[95 \% \mathrm{Cl}]$} & Pvalue & HR & {$[95 \% \mathrm{Cl}]$} & $P$ value \\
\hline Age & 1.00 & {$[0.92-1.08]$} & 0.979 & & & \\
\hline Male sex & NA & NA & NA & & & \\
\hline Multivessel disease & 2.29 & {$[0.66-7.63]$} & 0.185 & & & \\
\hline Number of implanted stents & 1.41 & [0.53-2.82] & 0.440 & & & \\
\hline Total length of the stent(s) & 1.01 & [0.99-1.03] & 0.266 & & & \\
\hline Active cancer & 12.81 & [2.44-235.57] & 0.001 & 9.03 & [1.33-176.69] & 0.023 \\
\hline ACS & 0.89 & {$[0.05-4.70]$} & 0.914 & & & \\
\hline Drug-eluting stent & 0.69 & {$[0.21-2.40]$} & 0.545 & & & \\
\hline Atrial fibrillation & 1.04 & {$[0.06-5.45]$} & 0.969 & & & \\
\hline LAD PCI & 1.46 & [0.42-6.69] & 0.563 & & & \\
\hline DAPT duration (months) & 0.99 & {$[0.91-1.04]$} & 0.711 & & & \\
\hline Chronic kidney disease & 0.97 & {$[0.21-3.36]$} & 0.966 & & & \\
\hline Hypertension & 0.88 & {$[0.27-3.36]$} & 0.840 & & & \\
\hline Dyslipidemia & 0.42 & {$[0.11-1.38]$} & 0.154 & & & \\
\hline Diabetes mellitus & 1.18 & [0.34-3.94] & 0.781 & & & \\
\hline Current smoker & 1.84 & {$[0.40-6.37]$} & 0.392 & & & \\
\hline Obesity & 0.56 & [0.03-2.93] & 0.548 & & & \\
\hline Previous cerebral infarction & NA & NA & NA & & & \\
\hline Previous myocardial infarction & 2.39 & {$[0.36-9.50]$} & 0.314 & & & \\
\hline Congestive heart failure & 1.30 & {$[0.07-7.03]$} & 0.810 & & & \\
\hline LVEF (\%) & 0.96 & {$[0.90-1.04]$} & 0.307 & & & \\
\hline LVDd & 0.97 & {$[0.85-1.09]$} & 0.572 & & & \\
\hline LVDs & 1.02 & {$[0.89-1.14]$} & 0.796 & & & \\
\hline Mitral regurgitation $\geq$ grade 3 & NA & NA & NA & & & \\
\hline Oral anticoagulant & 1.87 & {$[0.28-7.25]$} & 0.455 & & & \\
\hline$\beta$-blocker & 0.54 & {$[0.14-1.80]$} & 0.321 & & & \\
\hline ACE-I/ARB & 0.45 & {$[0.07-1.75]$} & 0.269 & & & \\
\hline Diuretics & 1.63 & {$[0.09-8.53]$} & 0.664 & & & \\
\hline Statin & 0.38 & {$[0.11-1.44]$} & 0.142 & & & \\
\hline Metastasis & 5.23 & [1.54-18.50] & $<0.01$ & 2.02 & {$[0.57-8.00]$} & 0.277 \\
\hline
\end{tabular}

Statistically undetermined values are described as "NA." No bleeding was observed in women and those who had previous coronary intervention or mitral regurgitation >type 3 .

ACE-I, angiotensin-converting enzyme inhibitor; ACS, acute coronary syndrome; ARB, angiotensin II receptor blocker; BARC, Bleeding Academic Research Consortium; DAPT, dual-antiplatelet therapy; LAD, left anterior descending artery; LVEF, left 
ventricular ejection fraction; $\mathrm{PCl}$, percutaneous coronary intervention; $\mathrm{HR}$, hazards ratio; $\mathrm{Cl}$, confidence interval.

Table 5. Cox Regression Hazards Model Analysis for 3P-MACEs

\begin{tabular}{|c|c|c|c|c|c|c|}
\hline \multirow[b]{2}{*}{ 3P MACE } & \multicolumn{3}{|c|}{ Univariate analysis } & \multicolumn{3}{|c|}{ Multivariate analysis } \\
\hline & HR & {$[95 \% \mathrm{Cl}]$} & $P$ value & HR & {$[95 \% \mathrm{Cl}]$} & $P$ value \\
\hline Age & 0.97 & {$[0.89-1.06]$} & 0.456 & & & \\
\hline Male sex & NA & NA & NA & & & \\
\hline Active cancer & 2.40 & {$[0.63-11.42]$} & 0.202 & & & \\
\hline ACS & 4.39 & {$[0.92-16.83]$} & 0.062 & 5.81 & {$[0.87-37.06]$} & 0.068 \\
\hline Drug-eluting stent & 0.45 & {$[0.11-1.72]$} & 0.239 & & & \\
\hline Atrial fibrillation & 2.71 & {$[0.40-11.25]$} & 0.261 & & & \\
\hline Residual coronary stenosis & 2.40 & {$[0.63-9.71]$} & 0.192 & & & \\
\hline Multivessel disease & 2.13 & {$[0.53-8.08]$} & 0.273 & & & \\
\hline Number of implanted stents & 1.98 & [0.92-3.63] & 0.0754 & 2.98 & {$[0.23-32.05]$} & 0.386 \\
\hline Total length of the stent(s) & 1.02 & {$[0.99-1.04]$} & 0.0830 & 0.98 & [0.92-1.05] & 0.629 \\
\hline LAD PCI & 1.09 & {$[0.29-5.17]$} & 0.902 & & & \\
\hline DAPT duration (months) & 0.93 & [0.92-1.02] & 0.171 & & & \\
\hline Chronic kidney disease & 2.15 & {$[0.53-8.14]$} & 0.265 & & & \\
\hline Hypertension & 0.39 & {$[0.10-1.46]$} & 0.157 & & & \\
\hline Dyslipidemia & 0.61 & {$[0.15-2.32]$} & 0.467 & & & \\
\hline Diabetes mellitus & 1.12 & {$[0.28-4.23]$} & 0.871 & & & \\
\hline Current smoker & 1.38 & {$[0.21-5.72]$} & 0.698 & & & \\
\hline Obesity & NA & NA & NA & & & \\
\hline Previous cerebral infarction & 2.33 & {$[0.35-9.66]$} & 0.332 & & & \\
\hline Previous myocardial infarction & 1.38 & {$[0.07-7.74]$} & 0.774 & & & \\
\hline Congestive heart failure & 4.26 & {$[0.62-18.37]$} & 0.122 & & & \\
\hline LVEF (\%) & 0.93 & {$[0.87-1.00]$} & 0.052 & 0.96 & {$[0.89-1.04]$} & 0.309 \\
\hline Mitral regurgitation $\geq$ type 3 & NA & NA & NA & & & \\
\hline Oral anticoagulant & 4.32 & {$[0.91-16.40]$} & 0.064 & & & \\
\hline$\beta$-blocker & 1.27 & {$[0.34-5.14]$} & 0.718 & & & \\
\hline ACE-I/ARB & 1.13 & {$[0.24-4.29]$} & 0.863 & & & \\
\hline Diuretics & NA & NA & NA & & & \\
\hline Statin & 1.97 & {$[0.36-36.62]$} & 0.485 & & & \\
\hline Metastasis & 1.22 & {$[0.18-5.17]$} & 0.812 & & & \\
\hline
\end{tabular}

Statistically undetermined values are described as "NA." No 3P-MACE was observed in those who were obese or took diuretics. 
ACE-I, angiotensin-converting enzyme inhibitor; ACS, acute coronary syndrome; ARB, angiotensin II receptor blocker; DAPT, dualantiplatelet therapy; LAD, left anterior descending artery; LVEF, left ventricular ejection fraction; $\mathrm{PCl}$, percutaneous coronary intervention; $\mathrm{HR}$, hazards ratio; $\mathrm{Cl}$, confidence interval.

\section{Figures}

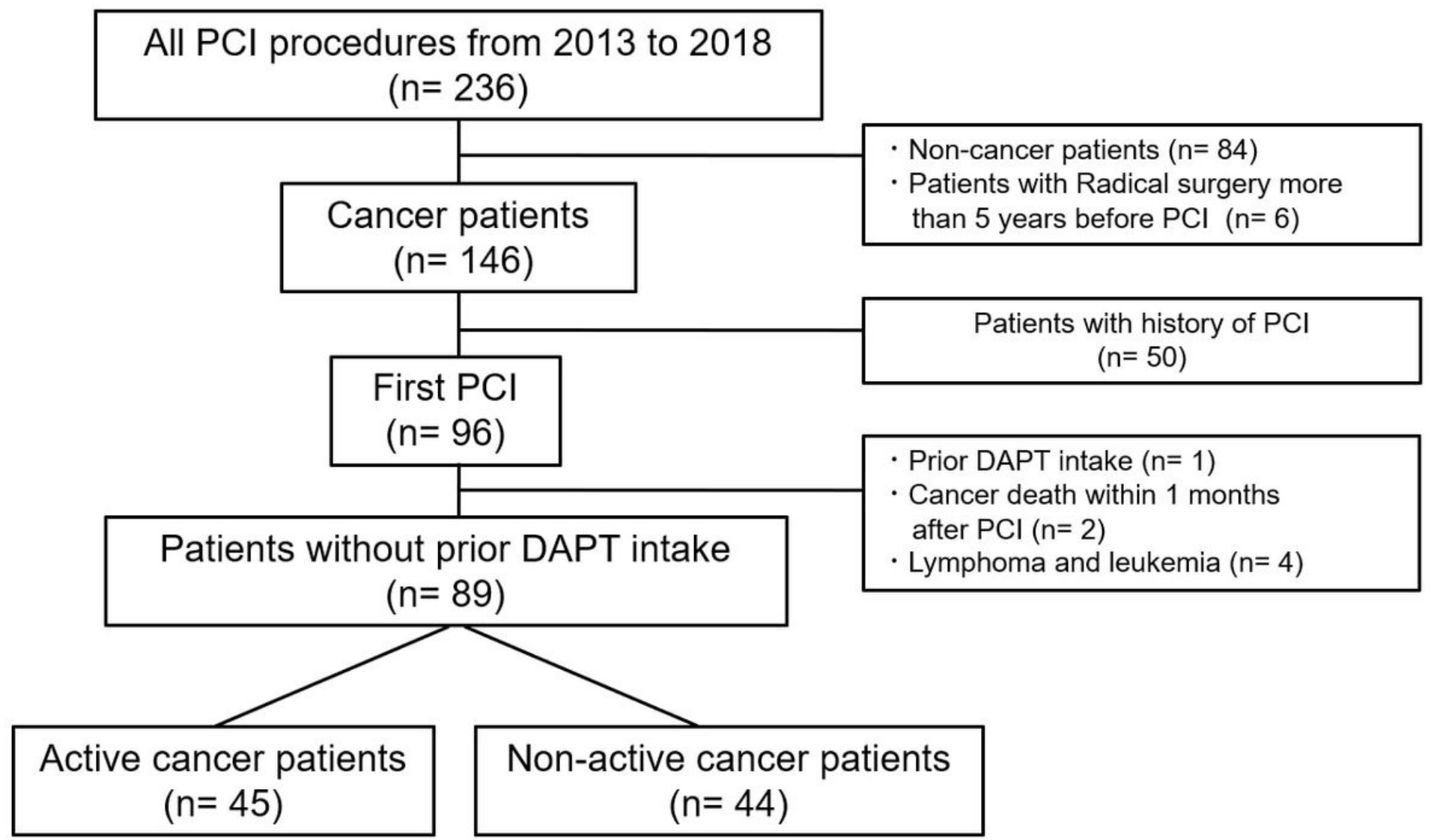

Figure 1

Study flowchart. 


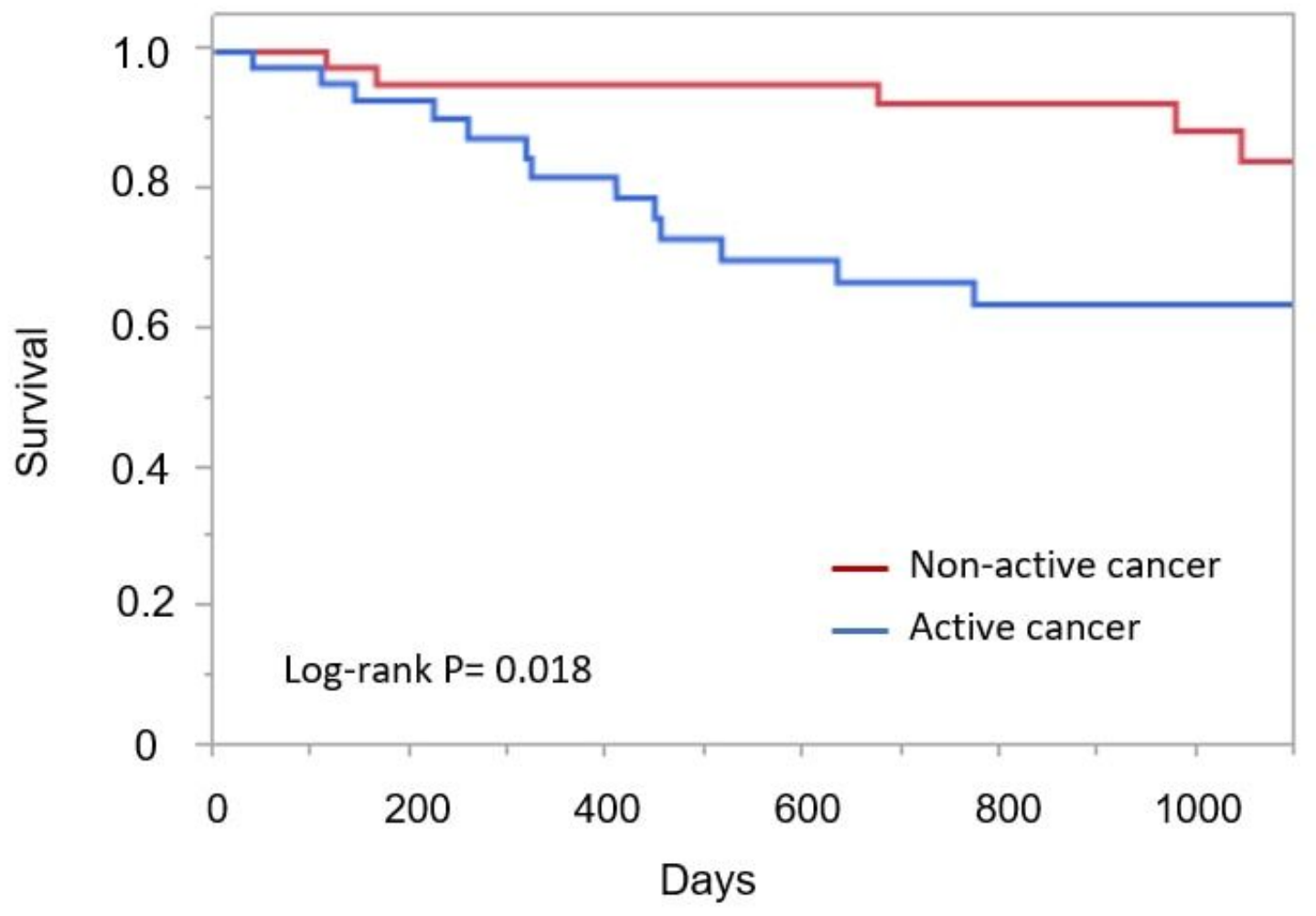

Figure 2

Kaplan-Meier analysis of all-cause survival for the active cancer $(n=45)$ and non-active cancer groups $(n=44)$. 
A

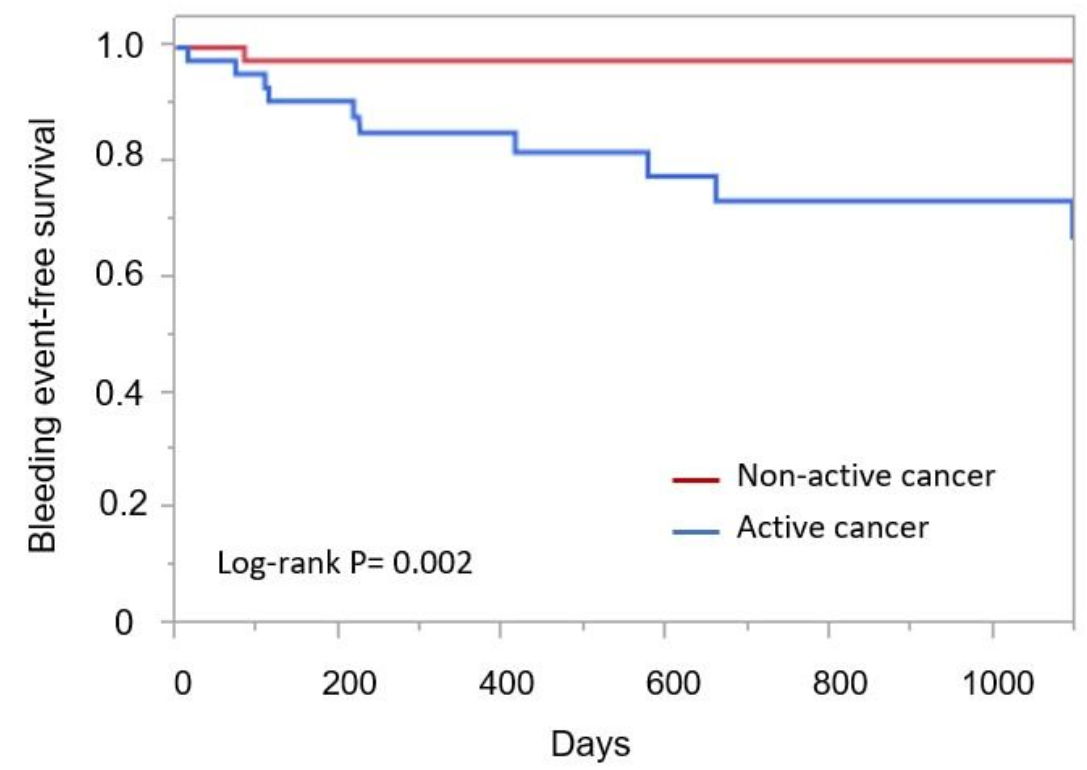

$\mathrm{B}$

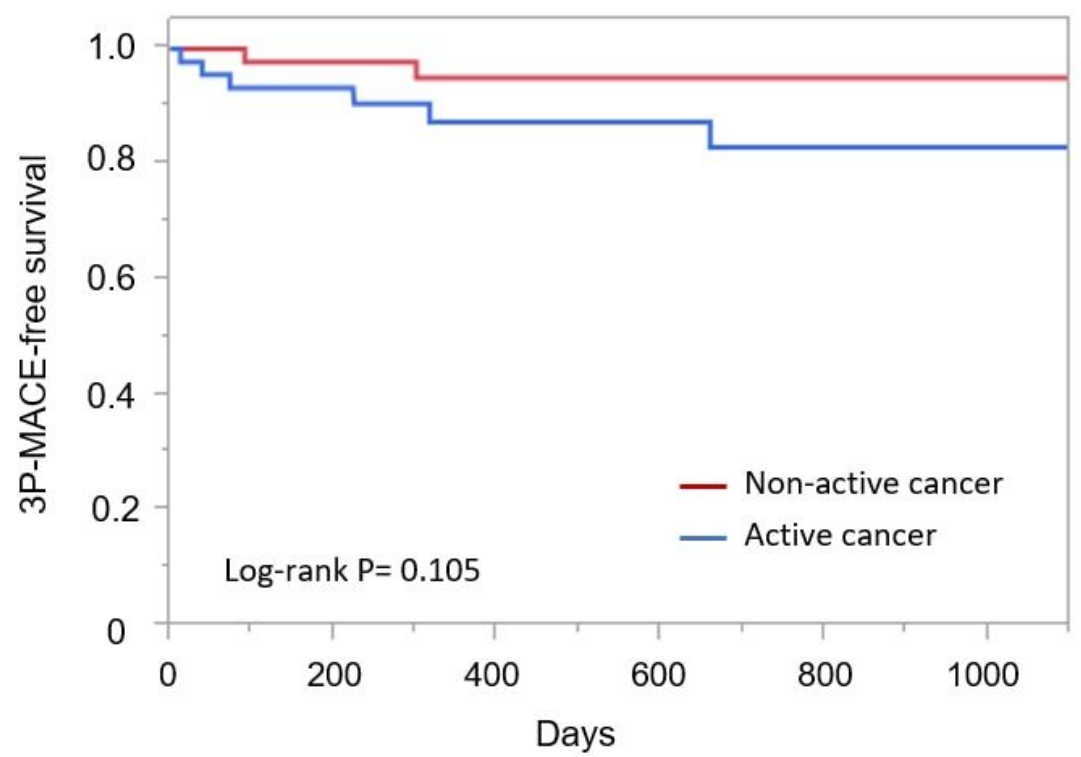

Figure 3

Kaplan-Meier analysis of the primary and secondary endpoints after PCl. (a) Survival free from bleeding of BARC types 2, 3, and 5 is compared between the active cancer group $(n=45)$ and the non-active cancer group $(n=44)$. (b) Survival free from 3P-MACE is compared between the active cancer group $(n=45)$ and the non-active cancer group $(n=44)$. 3P-MACE comprise cardiovascular death, nonfatal death, and nonfatal $\mathrm{MI}$. PCl, percutaneous coronary intervention; BARC, Bleeding Academic Research Consortium; 3P-MACE, 3-point major adverse cardiovascular events 